\title{
GÓRSKI GATUNEK CHAMAENERION PALUSTRE (ONAGRACEAE) W WIELKOPOLSCE
}

\author{
MOUNTAIN SPECIES CHAMAENERION PALUSTRE (ONAGRACEAE) \\ IN THE WIELKOPOLSKA REGION
}

\author{
Aneta Czarna
}

\begin{abstract}
A. Czarna, Katedra Botaniki, Uniwersytet Przyrodniczy w Poznaniu, ul. Wojska Polskiego 71c, 60-625 Poznań, Poland, e-mail: aneta.czarna@up.poznan.pl, (1) https://orcid.org/0000-0002-8687-7019
\end{abstract}

\begin{abstract}
AвSTRAct. Chamaenerion palustre is distributed in Poland mostly in mountains. It was found in the lowland of Wielkopolska at two ruderal localities on rocky substrates: in 2008 in the town of Buk on a railway siding, and in 2019 in the town of Głogów near railway tracks at the train station.
\end{abstract}

KEY WORD: Chamaenerion palustre, mountain species, Wielkopolska

Chamaenerion palustre Scop. 1771 [= Chamerion dodonaei (Vill.) Holub = Epilobium dodonaei Vill. = Epilobium rosmarinifolium Haenke $=$ E. angustissimum Weber] - wierzbówka nadrzeczna jest byliną lub półkrzewem. Ma liczne kwiaty i wzniesione, grube pączki (ryc. 1A). Kwiaty wierzbówki są duże, od 2,5 do $3,2 \mathrm{~cm}$ długości, szeroko rozpostarte. Płatki korony są odwrotnie jajowate, o długości 2-3 razy większej niż szerokość, na końcu zaokrąglone; działki wąskolancetowate (ryc. 1B). Owocem jest torebka, która ma od 4 do $6,5 \mathrm{~cm}$ długości, zwykle zaczerwieniona, krótko, przylegająco owłosiona, na szypułkach o długości od 0,8 do $1,75 \mathrm{~cm}$, podobnie owłosionych. Nasiona odwrotnie jajowato-wrzecionowate, długości od 1,43 do 1,82 mm, szerokości od 0,52 do 0,65 mm i powierzchni delikatnie brodawkowatej.

Wierzbówka nadrzeczna to gatunek środkowoeuropejsko-sub-irano-turański, osiągający w Polsce północno-wschodni, a częściowo północno-zachodni kres zasięgu (TACIK 1959). Jest górskim gatunkiem występującym naturalnie $\mathrm{w}$ niższych położeniach w Sudetach i Karpatach (ZająC 1996). Wzdłuż
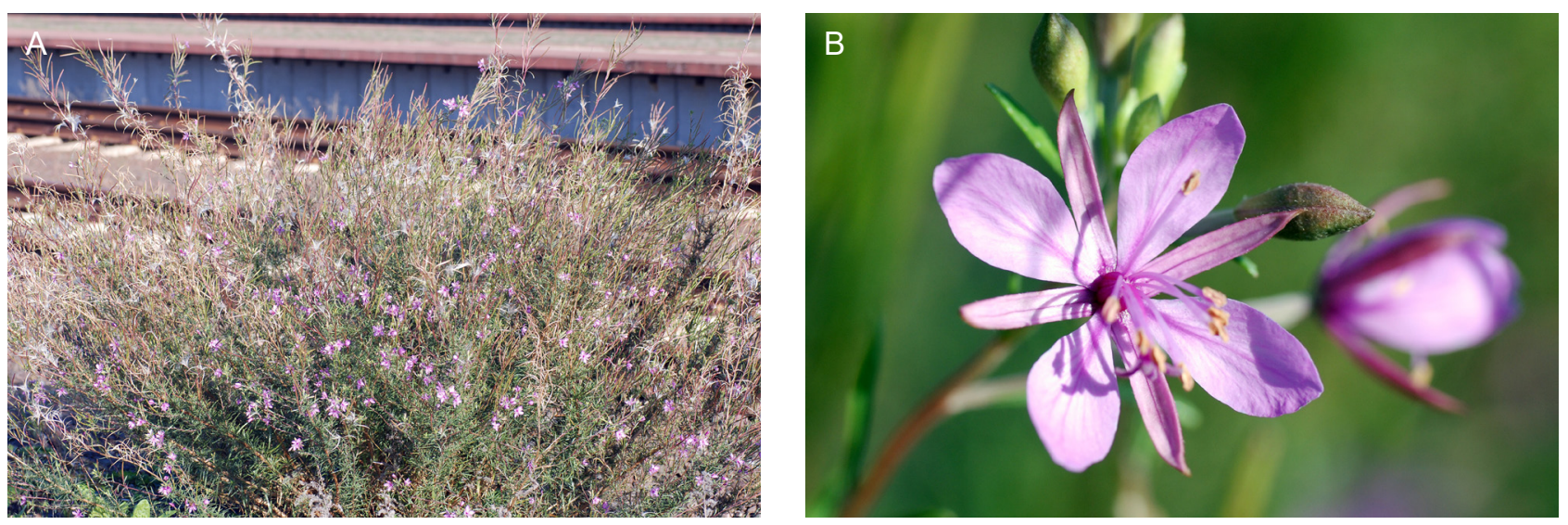

Ryc. 1. Chamaenerion palustre na torowisku bocznicy w Buku koło Poznania: A - pokrój, B - kwiat (31.08.2008, fot. A. Czarna)

Fig. 1. Chamaenerion palustre on a railway siding in Buk near Poznań: A - plant habit, B - flower (31.08.2008, photo: A. Czarna) 


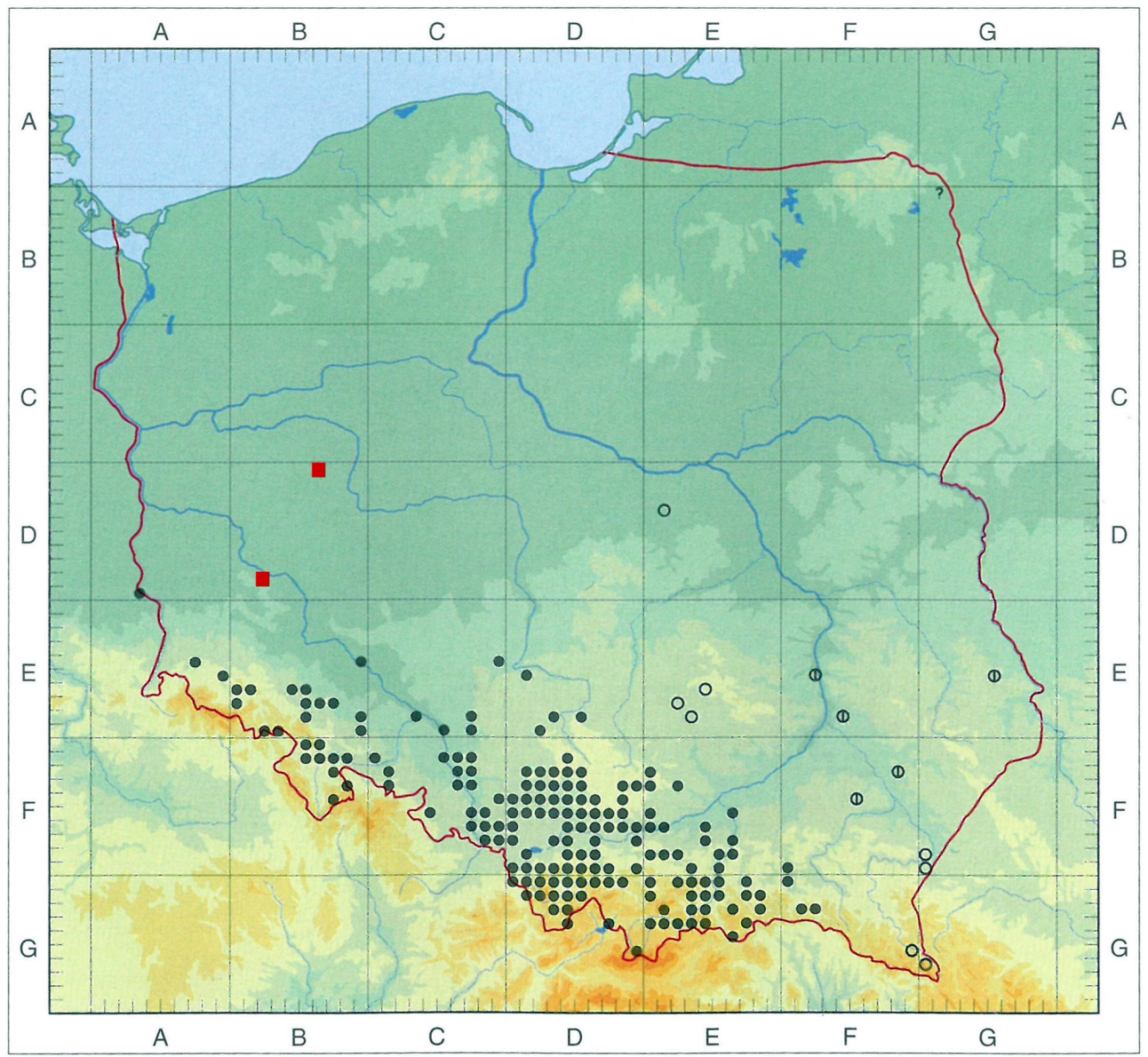

Ryc. 2. Rozmieszczenie wierzbówki nadrzecznej Chamaenerion palustre w Polsce (według ZAJĄC \& ZAJĄC 2001, uzupełnione); czerwony kwadrat - nowe stanowisko

Fig. 2. Distribution of Chamaenerion palustre in Poland (according to ZAJĄC \& ZAJĄC 2001, modified); red square - new locality

rzek schodzi na południowy niż (SzAFer i in. 1986), a także występuje na odosobnionych placówkach na wschodnim niżu (ZAJĄC \& ZAJĄC 2001).

Dwa nowo odkryte stanowiska Chamaenerion palustre są zlokalizowane $\mathrm{w}$ Wielkopolsce na kamienistych podłożach torowisk, na które dostały się wraz $z$ transportem kolejowym, mamy tu więc do czynienia $z$ agestochorią. Pierwsze stanowisko, zaobserwowane w 2008 roku, znajdowało się na bocznicy stacji PKP w Buku, gmina Buk, powiat poznański, województwo wielkopolskie (kwadrat ATPOL BD06) i składało się z jednego dużego okazu. Drugie, które odnotowano w 2019 roku, mieściło się na torowisku stacji PKP Głogów, gmina i powiat głogowski, województwo dolnośląskie (kwadrat ATPOL BD82) i składało się z trzech okazów. Stanowisko w Buku jest najbardziej na północ wysuniętym stanowiskiem w całej Polsce (ryc. 2). Skład florystyczny płatu $\mathrm{z}$ udziałem Chamaenerion palustre przedstawiają poniższe zdjęcie fitosocjologiczne.

Zdj. 1. Buk. Data wykonania zdjęcia: 31.08.2008, powierzchnia - $50 \mathrm{~m}^{2}$, liczba gatunków - 14 . Pokrycie warstwy A - 0\%, B - 0\%, C - 20\%. C: Chamaenerion palustre 1.1, Achillea millefolium +,
Chenopodium album + , Echium vulgare + , Petrorhagia prolifera + , Picris hieraciodes + , Rumex thyrsiflorus + , Taraxacum officinale +, Artemisia vulgaris $\mathrm{r}$, Lactuca serriola r, Lepidium virginicum $r$, Rumex crispus $r$, Sedum acre r, Sisymbrium loeselii $\mathrm{r}$.

Zdj. 2. Głogów. Data wykonania zdjęcia: 9.09.2019, powierzchnia - $50 \mathrm{~m}^{2}$, liczba gatunków - 19. Pokrycie warstwy A - 0\%, B - 5\%, C - 25\%. B: Betula pendula + , Salix purpurea + ; C: Calamagrostis epigejos 2.2, Chamaenerion palustre 1.1, Tanacetum vulgare 1.1, Poa compressa + , P. pratensis + , Rumex thyrsiflorus + , Silene vulgaris + , Solidago canadensis + , Chenopodium album r, Daucus carota r, Epilobium ciliatum r, Lepidium campestre $\mathrm{r}$, L. virginicum r, Picris hieraciodes r, Potentilla reptans $\mathrm{r}$, Reseda lutea r, Verbascum lychnitis $\mathrm{r}$.

Chamaenerion palustre na terenie Wielkopolski należy zaliczyć do roślin adwentywnych, a dokładnie do efemerofiów, i uwzględnić w nowym wydaniu krytycznej listy efemerofitów dla Wielkopolski. Poprzednie wydanie listy z 2017 roku (JАсKOWIAK i in. 2017) nie zawiera tego gatunku, choć pierwsze stanowisko jest znane już od 2008 roku. 
Głównym zagrożeniem dla istniejących okazów Chamaenerion palustre na obu omawianych stanowiskach jest ruch pociągów, a także przeładunek towarów na torowisku bocznicy. Jednak duża liczba zawiązywanych nasion może stać się źródłem rozprzestrzeniania się diaspor na inne miejsca na stwierdzonych stacjach PKP, a także na znaczne odległości. Jest to możliwe ze względu na organ lotny na nasionach. Dzięki temu opanowywane mogą być żwirowiska, zręby, rowy czy usypiska.

\section{LITERATURA}

Jackowiak B., Celka Z., Chmiel J., Latowski K., ŻuKOwsкI W. (2017): Checklist of the vascular flora of Wielkopolska (Poland): casual alien species. Biodiversity, Research and Conservation 46: 3555.

Szafer W., Kulczyński S., PaWłowski B. (1986): Rośliny polskie. PWN, Warszawa.

TACIK T. (1959): Rząd: Myrtales, Mirtowce. W: W. Szafer, B. Pawłowski (red.). Flora Polska. Rośliny naczyniowe Polski i ziem ościennych. PWN, Warszawa: 184-269.

ZajĄC A., ZająC M. (2001): Atlas rozmieszczenia roślin naczyniowych w Polsce. Pracownia Chorologii Komputerowej Instytutu Botaniki Uniwersytetu Jagiellońskiego, Kraków.

ZAJĄC M. (1996): Mountain vascular plants in the Polish lowlands. Polish Botanical Studies 11: 1-92. 